\title{
Young and old Pavlovian fear memories can be modified with extinction training during reconsolidation in humans
}

\author{
Elisa C.K. Steinfurth, ${ }^{1,2}$ Jonathan W. Kanen, ${ }^{1}$ Candace M. Raio, ${ }^{1}$ Roger L. Clem, ${ }^{3}$ \\ Richard L. Huganir, ${ }^{4}$ and Elizabeth A. Phelps ${ }^{1,5,6,7}$ \\ ${ }^{1}$ Department of Psychology, New York University, New York, New York 10003, USA; ${ }^{2}$ Department of Biological and Clinical \\ Psychology, University of Greifswald, Greifswald 17487, Germany; ${ }^{3}$ Departments of Neuroscience and Psychiatry, Friedman Brain \\ Institute, Icahn School of Medicine at Mt. Sinai, New York, New York 10029, USA; ${ }^{4}$ Department of Neuroscience, Howard Hughes \\ Medical Institute, Johns Hopkins University School of Medicine, Baltimore, Maryland 21205, USA; ${ }^{5}$ Center for Neural Science, New York \\ University, New York, New York 10003, USA; ${ }^{6}$ Nathan Kline Institute for Psychiatric Research, Orangeburg, New York 10962, USA
}

Extinction training during reconsolidation has been shown to persistently diminish conditioned fear responses across species. We investigated in humans if older fear memories can benefit similarly. Using a Pavlovian fear conditioning paradigm we compared standard extinction and extinction after memory reactivation $1 \mathrm{~d}$ or $7 \mathrm{~d}$ following acquisition. Participants who underwent extinction during reconsolidation showed no evidence of fear recovery, whereas fear responses returned in participants who underwent standard extinction. We observed this effect in young and old fear memories. Extending the beneficial use of reconsolidation to older fear memories in humans is promising for therapeutic applications.

[Supplemental material is available for this article.]

Learning to predict threat from cues in the environment is adaptive. In order to remain adaptive, however, the memory of the association between a neutral cue and a threat cue, as well as the elicited fear response or defensive behavior, needs to be flexibly modified as situations change. The standard approach to modify fear is extinction or exposure training in which a new, safe association is learned, leading to a gradually diminished fear expression. With extinction, however, fear might return because the original fear memory is not significantly altered and must be inhibited to express the new extinction memory (Bouton 2004). It has been suggested that the inability to consistently inhibit fear memories following extinction or exposure may be a factor in the maladaptive expression of fear in anxiety, trauma, or stress-related disorders, such as post-traumatic stress disorder (PTSD) (Rauch et al. 2006). The potentially temporary nature of extinction or exposure training led to the search for strategies to more persistently alter fear memories, which renewed interest in the post-retrieval memory process of reconsolidation. Reconsolidation is a restabilization process triggered by the retrieval of the original memory (Duvarci and Nader 2004). Interventions that interfere with reconsolidation can persistently alter the expression of fear memories (Nader et al. 2000; Schiller et al. 2010). However, to derive a viable therapeutic technique based on disrupting reconsolidation, it is critical that both recently formed and older fear memories can be altered. Since memories of trauma are often formed long before treatment opportunities are available, it is important to characterize the effectiveness of reconsolidation for older memories. To date, there is little evidence in humans demonstrating the efficacy of targeting reconsolidation to diminish the expression of fear memories

\footnotetext{
${ }^{7}$ Corresponding author

E-mail liz.phelps@nyu.edu

Article is online at http://www.learnmem.org/cgi/doi/10.1101//m.033589.113.

Freely available online through the Learning \& Memory Open Access option.
}

$>1 \mathrm{~d}$ old. The goal of the present study was to start to bridge this gap by targeting reconsolidation in 7-d-old fear memories.

Two primary techniques have been used to target the reconsolidation of fear memories: pharmacological and behavioral. These studies have examined fear memories using Pavlovian fear conditioning, in which an aversive unconditioned stimulus (UCS) is paired with a neutral conditioned stimulus (CS+). After a few pairings the CS+ acquires the ability to elicit a defensive or fear response, demonstrating the conditioned response (CR). Research in rodents has shown that Pavlovian fear acquisition, storage, and expression critically depend on the amygdala, with the lateral amygdala (LA) as the site of cued fear memory storage (LeDoux 2000).

Pharmacological studies have generally targeted the LA region when disrupting reconsolidation of cued fear memories. Since, like consolidation, reconsolidation requires protein synthesis (Nader et al. 2000; Alberini 2005), the direct infusion of a protein synthesis inhibitor (i.e., anisomycin) into the LA after CS+ reactivation eliminates the long-term expression of the $\mathrm{CR}$ in rats, presumably by disrupting the reconsolidation of the original fear memory (Nader et al. 2000). Several studies in rodents have shown that anisomycin can successfully disrupt the reconsolidation of older fear memories (14 d [Nader et al. 2000], $45 \mathrm{~d}$ [Debiec et al. 2002], $21 \mathrm{~d}$ [Frankland et al. 2006], $30 \mathrm{~d}$ [Einarsson and Nader 2012], $7 \mathrm{~d}$ [Hong et al. 2013]). These initial results are encouraging and suggest that disrupting reconsolidation may not depend on the age of the cued fear memory (but see Alberini 2011).

Since the use of anisomycin is toxic in humans, another line of research has focused on the noradrenergic system. In rats, blocking noradrenergic transmission with a $\beta$-adrenergic 
antagonist (i.e., propranolol) in the LA after reactivation of the $\mathrm{CS}+$ also appears to interfere with reconsolidation (Debiec and LeDoux 2004), whereas enhancing noradrenalin can facilitate it (Debiec et al. 2011). In rodents, propranolol has also been shown to effectively disrupt the reconsolidation of older conditioned fear memories (60 d [Debiec and LeDoux 2004], 2 d [Muravieva and Alberini 2010]). In humans, the use of propranolol to disrupt the reconsolidation of fear memories has yielded inconsistent findings (for review, see Lonergan et al. 2012). The vast majority of studies in humans have administered the drug prior to memory reactivation (e.g., Kindt et al. 2009; Poundja et al. 2012), thus potentially targeting memory retrieval, not reconsolidation (Muravieva and Alberini 2010). The few studies that have targeted the reconsolidation process with propranolol have demonstrated limited effectiveness (Soeter and Kindt 2012), with disruption of potentiated startle as a measure of fear memory expression, but not autonomic (i.e., skin conductance or SCR) or expectancy measures. A study attempting to target the reconsolidation of older fear memories in patients with PTSD administered propranolol or placebo after patients recalled personal traumatic events (Brunet et al. 2008). Patients given propranolol showed decreased autonomic measures of fear (i.e., SCR and heart rate) a week later, relative to the placebo group; however, this study lacked a nonreactivation control to rule out a general dampening effect of propranolol on autonomic arousal.

Given the toxic effects of most drugs used to target reconsolidation in animal models and the limited results in humans using propranolol, perhaps the most feasible approach is a behavioral intervention that modifies the learned association. The behavioral interference of reconsolidation is based on the premise that the purpose of reconsolidation is to allow an opportunity for an older memory to be updated or strengthened with subsequent retrieval. Precisely timing standard extinction training after memory reactivation to coincide with the reconsolidation process has been shown to result in persistent fear reduction in rodents (Monfils et al. 2009) and humans (Schiller et al. 2010), in comparison to standard extinction. In addition, the behavioral interference of reconsolidation results in plasticity-related changes in the LA in rodents (Monfils et al. 2009; Clem and Huganir 2010) and diminished blood oxygenation level dependent responses in the amygdala (Agren et al. 2012) and the prefrontal cortex (Schiller et al. 2013) in humans, supporting the notion that this behavioral technique can alter the original fear memory.

Although the effectiveness of this technique has not been investigated in older conditioned fear memories in humans, this has been explored in rodents, and appetitive memories have been examined in humans. Clem and Huganir (2010) found that the behavioral interference of reconsolidation of conditioned fear memories resulted in persistent fear reduction and enhanced synaptic plasticity within the LA, but only in 1-d-old memories. If they waited a week before performing the reconsolidation manipulation, the reactivation-extinction group did not differ from the standard extinction group. These results are in contrast to findings by Xue and colleagues (2012) examining appetitive conditioned place preference in rodents, and drug craving in human addicts. They found that a similar reactivation-extinction/exposure procedure designed to alter the reconsolidation of appetitive memories led to a lasting reduction in expression of 2-d-old conditioned place preference memories in rodents, and a craving reduction in addicts whose drug-taking memories are presumably much older.

To assess if older conditioned fear memories can be altered by behaviorally targeting reconsolidation in humans, we adapted a paradigm from Schiller et al. (2010), which demonstrated the long-term effectiveness of this manipulation in 1-d-old memories. Eighty healthy participants were included in the final analysis ( $n=79$ were excluded based on the studies' exclusion criteria) (see Supplemental Material for exclusion criteria, demographic information, and questionnaires). Participants were randomly assigned to one of the four experimental groups: Reactivation Day 1, No Reactivation Day 1, Reactivation Day 7, and No Reactivation Day 7. The experiment consisted of three sessions (Fig. 1). During the first session (Day 0) all participants underwent fear conditioning using a discrimination paradigm: one colored square (CS+) was paired with an aversive electric shock (UCS) on half of the trials (eight CS+US and eight CS+ trials, 50\% reinforcement), whereas a differently colored square $(\mathrm{CS}-$ ) was never paired with a shock (ten CS - ). Every trial consisted of a CS presentation ( $4 \mathrm{sec}$ ) followed by an inter-trial interval (10-12 sec) during which a fixation cross was presented. In CS + US trials a shock was administered $3.8 \mathrm{sec}$ after CS onset and coterminated with the CS.

The second session was conducted either 1 or $7 \mathrm{~d}$ after fear acquisition. Half of the participants underwent extinction training after memory reactivation (Reactivation groups) and the other half underwent standard extinction without prior memory reactivation (No Reactivation groups). In order to reactivate the original fear memory both Reactivation groups received a reminder cue (a single CS + trial) followed by a 10-min break during which a TV show episode (The Simpsons) was presented. Extinction training followed (i.e., the repeated presentation of CS+ and CSwithout reinforcement). Both No Reactivation groups watched the same TV show episode prior to extinction, but immediately after the experimental setup without any reminder cue (see Schiller et al. 2010). This design resulted in four groups: The Reactivation Day 1 group returned to the laboratory $24 \mathrm{~h}$ after the first session and received a reminder cue prior to extinction training. The No Reactivation Day 1 group also returned after $24 \mathrm{~h}$, but underwent extinction training only. The Reactivation Day 7 group returned after $7 \mathrm{~d}$ and received a reminder cue prior to extinction training whereas the No Reactivation Day 7 group returned after $7 \mathrm{~d}$ but did not receive a reminder cue. During extinction training all participants received $20 \mathrm{CS}-$ trials. The number of $\mathrm{CS}+$ trials was adjusted to account for the CS+ reminder trial (i.e., No Reactivation groups received $20 \mathrm{CS}+$ trials whereas Reactivation groups received only $19 \mathrm{CS}+$ trials).

The third session was conducted $1 \mathrm{~d}$ after the second session. The procedure was the same for all participants. To reinstate the fear memory, participants were exposed to four unsignaled shocks. After a 10-min break, during which all participants watched the same TV show episode (The Simpsons), a reextinction period followed (10 CS + and $10 \mathrm{CS}-$ ).

The CR was defined as the mean differential SCR response (i.e., mean $\mathrm{CS}+$ minus mean $\mathrm{CS}-$ ). Mean CRs were calculated for early (first four trials) and late (last four trials) acquisition and extinction. In order to examine the return of fear after

\begin{tabular}{ccc} 
Day 0 & Day 1 or Day 7 & Day 2 or Day 8 \\
\hline Acquisition & Reminder & Reinstatement \\
8 CS+US, 8 CS+, CS- & 1 CS + & $4 \times$ US \\
& 10 min & $10 \mathrm{~min} \mid$ \\
& & \\
& Extinction & Re-Extinction \\
& 19 CS + , 20 CS- & 10 CS,+ 10 CS- \\
\hline
\end{tabular}

Figure 1. Four different experimental groups: Reactivation Day 1, No Reactivation Day 1, Reactivation Day 7, and No Reactivation Day 7. All groups underwent acquisition on Day 0 . Half the groups returned a day later to undergo extinction training either with (Reactivation Day 1 group) or without (No Reactivation Day 1 group) a reminder and on Day 2 for fear reinstatement and reextinction. The other two groups returned a week later to undergo extinction training either with (Reactivation Day 7 group) or without (No Reactivation Day 7 group) a reminder cue. These two groups underwent reinstatement and reextinction on Day 8. 
reinstatement, we assessed the CR to the first trial of reextinction. Additionally, to assess the recovery of fear from extinction to reextinction we calculated a fear recovery index (i.e., late extinction CR minus first reextinction CR).

Fear acquisition was confirmed with a two-way analysis of variance (ANOVA), Group (Reactivation Day 1, No Reactivation Day 1, Reactivation Day 7, and No Reactivation Day 7) $\times$ Time (early and late CR). Participants' CR increased significantly over time $\left(F_{(3,79)}=19.21, P<0.001, \eta=0.20\right)$; there was no group effect or interaction. A follow-up $t$-test across all participants showed that the CR differed significantly from zero in both early $\left(t_{(79)}=\right.$ $8.3, P<0.001)$ and late $\left(t_{(79)}=15.27, P<0.001\right)$ acquisition. The same approach was used to confirm fear extinction. Participants' CR decreased significantly over time $\left(F_{(3,79)}=60.07, P<0.001\right.$, $\eta=0.44)$; there was no group effect or interaction. A follow-up $t$-test across all participants showed that participants' CR differed significantly from zero at the beginning of extinction $\left(t_{(79)}=8.5\right.$, $P<0.001$ ), but was not significantly different from zero at the end of extinction $\left(t_{(79)}=1.76, P=0.08\right)$. These results are not surprising given our exclusion criteria (see Supplemental Material) and demonstrate that participants successfully acquired and extinguished fear (Fig. 2).

To test for differences in reinstatement between groups, we conducted a one-way ANOVA for the first CR during reextinction. There was a main effect of group $\left(F_{(3,79)}=3.99, P<0.05\right)$. Independent samples $t$-tests showed that participants who underwent standard extinction training exhibited significantly higher CRs than those who received a reminder cue prior to extinction (No Reactivation Day 1 group vs. Reactivation Day 1 group, $t_{(38)}=2.36, P<0.05$; No Reaction Day 7 group vs. Reactivation Day 7 group, $\left.t_{(38)}=2.18, P<0.05\right)$. There was no difference between both Reactivation groups $\left(t_{(79)}=0.97, P=0.34\right)$ and between both No Reactivation groups $\left(t_{(79)}=0.87, P=0.39\right)$. Follow-up $t$-tests showed that the CR in both Reactivation groups was not significantly different from zero (Reactivation Day 1 group, $t_{(19)}=1.19, P=0.25$; Reactivation Day 7 group, $t_{(19)}=-0.25, P=$ $0.81)$. In contrast, in both No Reactivation groups the CR was significantly different from zero (No Reactivation Day 1 group, $t_{(19)}=4, P<0.01$; No Reactivation Day 7 group, $t_{(19)}=2.74, P<$ $0.05)$. Similar results were obtained when assessing the fear recovery index (see Supplemental Material).

The present findings suggest that, similar to young memories, older fear memories can also be updated using extinction training after memory reactivation. We showed that the extinction of 1-d-old and 7-d-old fear memories during the reconsolidation window successfully diminished the fear response after fear reinstatement. These results are consistent with rodent studies using pharmacological blockade of reconsolidation to successfully modify older fear memories (Nader et al. 2000; Debiec et al. 2002). They offer support for the notion that memories are suscep-

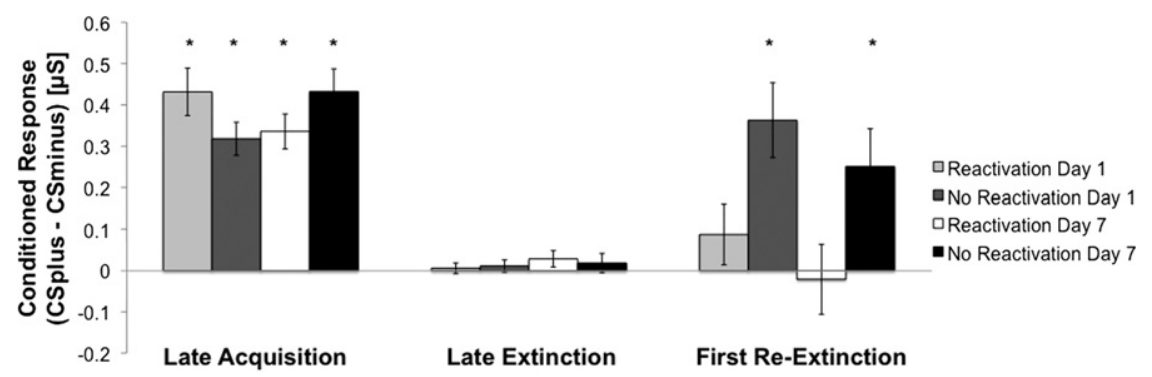

Figure 2. Participants in all groups showed an increased $C R$ after fear acquisition (Day 0 ) and a diminished CR after extinction (Day 1 or Day 7). The CR during reextinction after fear reinstatement (Day 2 or Day 8 ) was increased only in the No Reactivation groups. tible to modification even after initial consolidation is terminated when new, safe information is introduced during reconsolidation. This further underscores the adaptive value of reconsolidation.

Interestingly, the present results are incongruent with the findings of Clem and Huganir (2010), who showed that a comparable behavioral intervention in mice did not prevent the return of 7-d-old fear memories. This might suggest some differences in age-related memory processes between species, specifically that the susceptibility of memories to modifications lasts longer in humans vs. rodents. However, notable differences between these studies might also explain the opposing results. First, the strength of the fear memory might differ. We observed robust fear conditioning in our final sample, although we excluded around 50\% of our initial study population because the conditioning or extinction effects were not robust (see Supplemental Material for exclusion criteria). Due to ethical constraints, laboratory-generated fear memories in humans are always mild. Second, although the molecular mechanisms of memory aging are similar across species, the time line might be different. A simple comparison based on the different life expectancies in humans $(\sim 70 \mathrm{yr})$ and mice $(\sim 2$ yr) shows that $7 \mathrm{~d}$ in mice roughly equal $70 \mathrm{~d}$ in humans (see Quinn 2005).

Suzuki et al. (2004) addressed both of these concernsstrength and age of memory-in a contextual fear conditioning study in mice. The authors showed that reconsolidation of stronger contextual fear memories (i.e., three foot shocks instead of one) could not be blocked with anisomycin. However, if the reactivation was intensified (i.e., longer reexposure to the training context), anisomycin resulted in a diminished fear response. In a similar vein, older contextual fear memories ( $8 \mathrm{wk}$ ) were not susceptible to change by pharmacological manipulation unless prolonged reactivation sessions were conducted (Suzuki et al. 2004). These results suggest that older and stronger fear memories can also be updated under the right circumstances. Therefore, one could speculate that a behavioral intervention in mice after a prolonged memory reactivation period might also render older fear memories labile and lead to a persistently diminished fear response. However, it is necessary to examine this in future research.

It should be noted that the present study was intended to closely mirror the nonhuman animal research that inspired us (Clem and Huganir 2010), and therefore has two limitations. First, we excluded participants who showed no evidence of fear acquisition or extinction from further participation. In studies examining techniques to diminish fear (e.g., extinction and reconsolidation) across species this is a common exclusion criterion because fear acquisition and extinction are prerequisites to study fear recovery following manipulations of reconsolidation (e.g., Yang et al. 2006; Sotres-Bayon et al. 2009; Kindt and Soeter 2011). However, fear conditioning procedures typically used in humans are less robust in rodents for a few reasons. First, ethical constraints require the intensity of the UCS to be relatively mild and not painful (see above), thus reducing its aversive nature. Second, the strength of the noninvasive, autonomic physiological response typically assessed in human fear conditioning (i.e., SCR) can vary with participants' race (Johnson and Landon 1965), age, sex, as well as the weather and room temperature (Venables and Mitchell 1996). We did not control for these factors in participant selection or data collection. Due to these constraints, we excluded a significantly higher proportion of participants who failed to meet the exclusion criteria than would 
be typical in research with rodents, but the criteria were the same. Second, we did not acquire UCS expectancy ratings, a cognitive measure on which participants indicate the likelihood of the UCS on each trial and which is used in some human fear conditioning studies. Although the use of this measure may have resulted in a more robust assessment of fear conditioning and the loss of fewer participants, we chose not to use it because assessing explicit cognitive knowledge is obviously not possible in research in rodents and would have limited the generalizability between our paradigm and the findings in rodents. In addition, emphasizing explicit knowledge of the CS-UCS relationship has been shown to alter the nature of fear learning (Olsson and Phelps 2004; Atlas et al., pers. comm.) and the neural substrates mediating this learning (Funayama et al. 2001; Coppens et al. 2009). For these reasons, we limited our fear assessment to a noninvasive, autonomic measure.

The present study is an important step in further characterizing the boundaries within which reconsolidation update mechanisms are viable in humans. As research on reconsolidation progresses, it is becoming increasingly clear that several factors are linked to the effectiveness of targeting reconsolidation to prevent fear (Auber et al. 2013). Understanding the boundary conditions (e.g., strength and age of memory) is critical in order to translate these findings to useful clinical interventions. The present results are only an initial step toward understanding the potential temporal limitations of reconsolidation and further studies with fear memories older than $4 \mathrm{wk}$ are necessary to match the temporal characteristics of PTSD and to distinguish if these results can potentially be translated to acute traumatic fear memories or also to older traumatic fear memories (DSM V, American Psychiatric Association 2013). The present results, however, suggest that the behavioral interference with the reconsolidation of fear memories could be a useful technique to modify fear memories regardless of their age.

\section{Acknowledgments}

We thank Tory Toole for support with the data collection and Daniela Schiller for support with the data interpretation. E.A.P. was supported by RO1MH097085. E.C.K.S. was supported by the Graduate Program of the German Federal State MecklenburgVorpommern and by the German Academic Exchange Service (DAAD).

\section{References}

Agren T, Engman J, Frick A, Bjorkstrand J, Larsson EM, Furmark T, Fredrikson M. 2012. Disruption of reconsolidation erases a fear memory trace in the human amygdala. Science 337: 1550-1552.

Alberini CM. 2005. Mechanisms of memory stabilization: Are consolidation and reconsolidation similar or distinct processes? Trends Neurosci 28: 51-56.

Alberini CM. 2011. The role of reconsolidation and the dynamic process of long-term memory formation and storage. Front Behav Neurosci 5: 1-10.

American Psychiatric Association. 2013. Diagnostic and statistical manual of mental disorders, 5th ed. American Psychiatric Publishing, Arlington, VA.

Auber A, Tedesco V, Jones CE, Monfils M-H, Chiamulera C. 2013. Post-retrieval extinction as reconsolidation interference: methodological issues or boundary conditions? Psychopharmacology 226: $631-647$.

Bouton ME. 2004. Context and behavioral processes in extinction. Learn Mem 11: $485-494$.

Brunet A, Orr SP, Tremblay J, Robertson K, Nader K, Pitman RK. 2008. Effect of post-retrieval propranolol on psychophysiologic responding during subsequent script-driven traumatic imagery in post-traumatic stress disorder. J Psychiatr Res 42: 503-506.

Clem RL, Huganir RL. 2010. Calcium-permeable AMPA receptor dynamics mediate fear memory erasure. Science 330: 1108-1112.

Coppens E, Spruyt A, Vandenbulcke M, Van Paesschen W, Vansteenwegan D. 2009. Classically conditioned fear responses are preserved following unilateral temporal lobectomy in humans when concurrent US-expectancy ratings are used. Neuropsychologia 47: 2496-2503. Debiec J, LeDoux JE. 2004. Disruption of reconsolidation but not consolidation of auditory fear conditioning by noradrenergic blockade in the amygdala. Neuroscience 129: 267-272.

Debiec J, LeDoux JE, Nader K. 2002. Cellular and systems reconsolidation in the hippocampus. Neuron 36: 527-538.

Debiec J, Bush DEA, LeDoux JE. 2011. Noradrenergic enhancement of reconsolidation in the amygdala impairs extinction of conditioned fear in rats-a possible mechanism for the persistence of traumatic memories in PTSD. Depress Anxiety 28: 186-193.

Duvarci S, Nader K. 2004. Characterization of fear memory reconsolidation. J Neurosci 24: 9269-9275.

Einarsson EÖ, Nader K. 2012. Involvement of the anterior cingulate cortex in formation, consolidation, and reconsolidation of recent and remote contextual fear memory. Learn Mem 19: 449-452.

Frankland PW, Ding H-K, Takahashi E, Suzuki A, Kida S, Silva AJ. 2006. Stability of recent and remote contextual fear memory. Learn Mem 13: $451-457$.

Funayama ES, Grillon C, Davis M, Phelps EA. 2001. A double dissociation in the affective modulation of startle in humans: effects of unilateral temporal lobectomy. J Cogn Neurosci 13: 721-729.

Hong I, Kim J, Kim J, Lee S, Ko H, Nader K, Kaang B. 2013. AMPA receptor exchange underlies transient memory destabilization on retrieval. Proc Natl Acad Sci 110: 8218-8223.

Johnson LC, Landon MM. 1965. Eccrine sweat gland activity and racial differences in resting skin conductance. Psychophysiology 1: 322-329.

Kindt M, Soeter M. 2011. Reconsolidation in a human fear conditioning study: a test of extinction as updating mechanism. Biol Psychol 92: 43-50.

Kindt M, Soeter M, Vervliet B. 2009. Beyond extinction: erasing human fear responses and preventing the return of fear. Nat Neurosci 12: 256-258.

LeDoux JE. 2000. Emotional circuits in the brain. Annu Rev Neurosci 23: $155-184$.

Lonergan MH, Olivera-Figueroa LA, Pitman RK, Brunet A. 2012. Propranolol's effects on the consolidation and reconsolidation of long-term emotional memory in healthy participants: a meta-analysis. J Psychiatry Neurosci 37: 222-231.

Monfils M-H, Cowansage KK, Klann E, LeDoux JE. 2009. Extinctionreconsolidation boundaries: key to persistent attenuation of fear memories. Science 324: 951-955.

Muravieva EV, Alberini CM. 2010. Limited efficacy of propranolol on the reconsolidation of fear memories. Learn Mem 17: 306-313.

Nader K, Schafe GE, LeDoux JE. 2000. Fear memories require protein synthesis in the amygdala for reconsolidation after retrieval. Nature 406: $722-726$.

Olsson A, Phelps EA. 2004. Learned fear of "unseen" faces after Pavlovian, observational, and instructed fear. Psychol Sci 15: 822-828.

Poundja J, Sanche S, Tremblay J, Brunet A. 2012. Trauma reactivation under the influence of propranolol: an examination of clinical predictors. Eur J Psychotraumatol 3: 15470.

Quinn R. 2005. Comparing rat's to human's age: How old is my rat in people years? Nutrition 21: 775-777.

Rauch SL, Shin LM, Phelps EA. 2006. Neurocircuitry models of posttraumatic stress disorder and extinction: Human neuroimaging research-past, present, and future. Biol Psychiatry 60: 376-382.

Schiller D, Monfils M-H, Raio CM, Johnson DC, LeDoux JE, Phelps EA. 2010. Preventing the return of fear in humans using reconsolidation update mechanisms. Nature 463: 49-53.

Schiller D, Kanen JW, LeDoux JE, Monfils M-H, Phelps EA. 2013. Extinction during reconsolidation of threat memory diminishes prefrontal cortex involvement. Proc Natl Acad Sci 110: 20040-20045.

Soeter M, Kindt M. 2012. Stimulation of the noradrenergic system during memory formation impairs extinction learning but not the disruption of reconsolidation. Neuropsychopharmacology 37: 1204-1215.

Sotres-Bayon F, Diaz-Mataix L, Bush DE, LeDoux JE. 2009. Dissociable roles for the ventromedial prefrontal cortex and amygdala in fear extinction: NR2B contribution. Cereb Cortex 19: 474-482.

Suzuki A, Josselyn SA, Frankland PW, Masushige S, Silva AJ, Kida S. 2004 Memory reconsolidation and extinction have distinct temporal and biochemical signatures. J Neurosci 24: 4787-4795.

Venables PH, Mitchell DA. 1996. The effects of age, sex and time of testing on skin conductance activity. Biol Psychol 43: 87-101.

Xue Y-X, Luo Y-X, Wu P, Shi H-S, Xue L-F, Chen C, Zhu W-L, Ding Z-B, Bao Y-P, Shi J, et al. 2012. A memory retrieval-extinction procedure to prevent drug craving and relapse. Science 336: 241-245.

Yang Y-L, Chao P-K, Lu K-T. 2006. Systemic and intra-amygdala administration of glucocorticoid agonist and antagonist modulate extinction of conditioned fear. Neuropsychopharmacology 31: 912-924.

Received October 15, 2013; accepted in revised form March 30, 2014. 


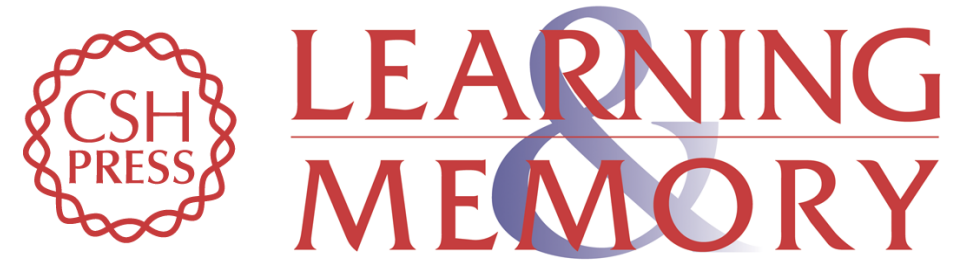

\section{Young and old Pavlovian fear memories can be modified with extinction training during reconsolidation in humans}

Elisa C.K. Steinfurth, Jonathan W. Kanen, Candace M. Raio, et al.

Learn. Mem. 2014, 21:

Access the most recent version at doi:10.1101/Im.033589.113

\section{Supplemental http://learnmem.cshlp.org/content/suppl/2014/06/04/21.7.338.DC1 Material}

References This article cites 36 articles, 12 of which can be accessed free at: http://learnmem.cshlp.org/content/21/7/338.full.html\#ref-list-1

Creative This article, published in Learning \& Memory, is available under a Creative Commons Commons License (Attribution-NonCommercial 4.0 International), as described at License http://creativecommons.org/licenses/by-nc/4.0/.

Email Alerting Receive free email alerts when new articles cite this article - sign up in the box at the Service top right corner of the article or click here. 